\title{
Literatura no Currículo da Escola Capixaba de Ensino Médio ${ }^{1}$
}

\section{Literature in the curriculum of high schools of the state of Espirito Santo in Brazil}

\author{
Maria Amélia Dalvi²
}

\begin{abstract}
RESUMO
Tomando-se o currículo básico da escola estadual de nível médio do estado brasileiro do Espírito Santo, no âmbito da disciplina escolar de Língua Portuguesa, estudam-se as orientações, normatizações e prescrições no tocante ao trabalho com a literatura. Esse corpus documental é lido à luz de pesquisas contemporâneas sobre o ensino da literatura e a educação literária para o trabalho com a literatura na escola, visando a identificar filiações teóricas, tendências e rumos no que se refere a parâmetros e propostas oficiais, no contexto capixaba, para o ensino da literatura e da leitura literária, contribuindo para a ampliação de sua compreensão. Depreende-se, nas análises, que haja a permanência de perspectivas tradicionais (como o foco na relação diretiva entre contexto social e produção literária e na historiografia positivista), todavia em correlação com mudanças requeridas por concepções renovadas ou renovadoras, tais como o foco na interação texto-leitor e na constituição da subjetividade leitora.
\end{abstract}

Palavras-chave: currículo; educação literária; ensino médio; Espírito Santo.

\begin{abstract}
The guidelines, regulations and prescriptions related to the class work with literature in Portuguese Language were analyzed taking the basic curriculum of high schools of the state of Espirito Santo, Brazil. This body of information was interpreted taking into account contemporary research
\end{abstract}

DOI: $10.1590 / 0104-4060.36288$

1 Esta pesquisa é financiada por convênio entre a Fundação de Amparo à Pesquisa do Espírito Santo (Fapes) e o Conselho Nacional de Desenvolvimento Científico e Tecnológico (CNPq).

2 Universidade Federal do Espírito Santo. Programas de Pós-Graduação em Educação e em Letras. Vitória, Espírito Santo, Brasil. Av. Fernando Ferrari, 514, Centro de Educação, Campus Universitário de Goiabeiras. CEP 29075-910. 
on literature teaching and literary education for the work with literature at school in order to identify theoretical affiliations, trends and pathways of the state's official proposals and parameters, considering its context on literature and literary reading education, having a larger understanding on that issue. We conclude that there is persistence of traditional perspectives, focusing the directive relationship between social context and literary production and in a positivist historiography, even though they are correlated with the changes demanded by renovating or renewed concepts, such as the focus on text-reader interaction and on the constitution of subjective reading.

Keywords: curriculum; literary education; high school; Espirito Santo.

\section{Considerações iniciais}

Neste artigo, apresentam-se e discutem-se orientações, normatizações e prescrições para o trabalho com a literatura e a leitura literária, no Currículo Básico da Escola Estadual do Espírito Santo (CBEE-ES) para o ensino médio, no que diz respeito à disciplina de Língua Portuguesa, no estado brasileiro do Espírito Santo (ES). No desenvolvimento do texto, primeiramente, contextualiza-se e apresenta-se o documento curricular e seu campo de emergência, incorporando-se reflexões já publicadas na mesma ambiência temática. Em seguida, busca-se identificar filiações teóricas, tendências e rumos no que se refere a parâmetros e propostas oficiais para o trabalho com a literatura e a leitura literária, contribuindo para sua compreensão crítica e, consequentemente, para o engendramento de políticas mais conscientes nesse domínio.

A identificação de filiações teóricas, tendências e rumos no que se refere a parâmetros e propostas oficiais, por meio dos documentos curriculares, para o trabalho com a literatura e a leitura literária poderia contribuir para sua compreensão crítica e para a proposição de outras políticas por pelo menos dois motivos: a) de acordo com Berenblum (2003), os Currículos Nacionais servem como elementos de controle, donde decorre a necessidade de avaliação do conhecimento do aluno em provas que prezam pelos conteúdos chamados básicos, indicados nos currículos - o que explica a importância do estudo dos “Currículos Nacionais" e, subsidiariamente, dos “Currículos Estaduais"; e b) de acordo com Silva (2005), "a igualdade depende de uma modificação substancial do currículo existente. Não haverá ‘justiça curricular' [...] se o cânon curricular não for modificado para refletir as formas pelas quais a diferença é produzida por relações sociais de assimetria" (p. 90). 
Nasceu de uma constatação obtida a partir de levantamento bibliográfico a investigação que este trabalho sintetiza: há poucos estudos de currículos básicos de diferentes redes para o ensino médio, na contemporaneidade, e ainda mais particularmente no âmbito da disciplina de Língua Portuguesa, com foco específico nas prescrições e recomendações oficiais para o trabalho com a literatura e a leitura literária. No Portal de Periódicos da Coordenação de Aperfeiçoamento de Pessoal de Nível Superior (Capes), há, por exemplo: a) estudos brasileiros, como o de Silva (2009) - que faz um recorte específico do trabalho com gêneros no estado do Rio de Janeiro; e b) estudos portugueses, como os de Pinto (2003), Bento (2009) e Soares (2011) - que visam a compreender o estatuto curricular da disciplina de Língua Portuguesa e sua recontextualização política e pedagógica, em Portugal ou em Timor-Leste. Mas não há coincidência com o escopo e corpus que propomos. Dessa forma, após levantamento no Banco de Teses e Dissertações da Capes, não foi possível acessar trabalho final de pós-graduação (mestrado ou doutorado) que tomasse o contemporâneo (no sentido de "vigente") currículo básico, como o da rede estadual do Espírito Santo, para o ensino médio com o recorte pretendido (a saber, o trabalho com a literatura e a leitura literária).

Parece-nos, contudo, a despeito de sua incipiência, que um estudo da natureza do que realizamos é importante por pelo menos dois motivos: a) porque o currículo em questão emana de outros documentos oficiais nacionais (Lei de Diretrizes e Bases da Educação Nacional, Parâmetros Curriculares Nacionais, Orientações Curriculares Nacionais) e de um dado contexto de "atualidade do conhecimento" da área aqui nomeada como Ensino de Língua e Literatura, contudo, deixando ver diferentes modos específicos de compreensão e apropriação desses documentos e dessa "atualidade do conhecimento" na área; e b) porque possibilita detectar permanências e transformações que, possivelmente, não se circunscrevem a uma particularidade regional (no caso, a do estado do Espírito Santo) e indiciam movimentos mais amplos do ponto de vista das discussões educacionais - e, no nosso caso particular, das discussões atinentes ao trabalho com a literatura e a leitura literária.

Especificamente, no que diz respeito às particularidades regionais, de acordo com dados disponibilizados pelo programa "Todos pela Educação" com base em dados do Instituto Brasileiro de Geografia e Estatística, é importante dizer que o Espírito Santo, em 2010, tinha uma população de 3.514 .952 pessoas, das quais 800.005 estavam em idade escolar; a renda per capita média era de

3 Utilizamos a expressão por se tratar de expressão consagrada na pesquisa acadêmico-científica, contudo, não nos parece que nenhuma área tenha uma única versão de "atualidade do conhecimento", havendo apropriações diferentes e mesmo conflitantes. 
$\mathrm{R} \$ 691,00$; e a taxa de analfabetismo, $0,7 \%$ para pessoas de 10 a 14 anos e $6,4 \%$ para pessoas com 15 anos ou mais (concentradas maciçamente na zona rural). A título de comparação, é interessante notar: a) a população do estado representa apenas $4,37 \%$ da população da região sudeste (composta de 80.364 .410 pessoas); b) a população em idade escolar no Espírito Santo representa 22,76\% do conjunto da população, enquanto no sudeste como um todo essa população em idade escolar representa cerca de 21,56\%; c) a renda per capita do Espírito Santo é menor que a renda média da região; e d) a taxa de analfabetismo para pessoas com 15 anos ou mais é significativamente maior que a taxa da região (NÚMEROS..., 2014).

Complementarmente, é necessário acrescentar que, das 31 universidades públicas existentes no Sudeste, o ES conta com uma única instituição (Ufes), na qual funciona um único programa de pós-graduação em Educação (mestrado e doutorado), com cerca de 35 anos de funcionamento - e também um único programa de pós-graduação em Linguística (mestrado), com cerca de 10 anos de funcionamento, e um único programa de pós-graduação em Letras (mestrado e doutorado), com cerca de 20 anos de funcionamento, que poderiam ser outros possíveis lócus de realização de pesquisas como a que aqui sintetizamos. Esse cenário, quando comparado aos outros estados da região Sudeste (Minas Gerais, Rio de Janeiro e São Paulo), pode ajudar a entender fragilidades e potencialidades do documento aqui analisado e desse estudo exploratório que dele se faz.

Do ponto de vista metodológico, nos apropriamos de algumas das propostas de Marildes Marinho (2007), em "Currículos da escola brasileira: elementos para uma análise discursiva”. A autora postula que, no Brasil, quando se estudam as disciplinas escolares, necessariamente três questões se atravessam: a) o que, como e para que se estuda quando se estuda, por exemplo, "língua portuguesa" como disciplina escolar?; b) quais são as estratégias textuais ou discursivas que formulam a imagem do leitor-professor, nos momentos da sua formação inicial e continuada - e, acrescentamos, no momento de produção de documentos oficiais a ele destinados; e c) quais são os princípios teórico-metodológicos que permitem a análise dos textos ou discursos pedagógicos, como é o caso da análise de currículos e documentos correlatos?

Particularmente, no que diz respeito a essa última questão - que é a que nos interessa mais de perto -, Marinho (2007) defende que é necessário perguntar: "quem escreve, para quem, como escreve, e quais seriam os efeitos dessa relação de interlocução?” (p. 164), havendo, assim, a necessidade de analisar o currículo como prática de linguagem contextualizada socioculturalmente. As propostas de Marinho (2007) coadunam-se à observação de Chartier (1988): "As representações do mundo social [...] embora aspirem à universalidade de um diagnóstico fundado na razão, são sempre determinadas pelos interesses de 
grupo que as forjam. Daí para cada caso, o necessário relacionamento dos discursos proferidos com a posição de quem os utiliza" (p. 17), o que reforçaria a coerência teórico-metodológica de nossa proposta. Isso posto, passamos, a seguir, à contextualização e à apresentação do documento curricular que investigamos.

\section{O CBEE-ES e um recorte em torno da literatura e da leitura literária}

Uma proposta de apresentação geral do currículo e de discussão de seus fundamentos

O Currículo Básico da Escola Estadual do Espírito Santo (CBEE-ES) foi publicado em 2009 - ou seja, cerca de uma década depois dos Parâmetros Curriculares Nacionais (PCNs, respectivamente, de 1997 e 1998, dedicados aos anos iniciais e aos anos finais do ensino fundamental; e de 2000 os dedicados ao ensino médio). Ou seja, o CBEE-ES vem a público em um contexto em que já há consistente literatura crítica sobre os documentos emanados pelo Ministério da Educação (MEC) e mesmo a revisão, pelo próprio MEC, de vários desses documentos (como ocorreu, por exemplo, com a publicação, em 2004, das Orientações Curriculares Nacionais - BRASIL, 2004 - para o ensino médio, que problematizam de maneira bastante crítica os Parâmetros que lhes antecedem, em muitos momentos negando-os).

O CBEE-ES conta com um "Guia de Implementação", um volume para os anos iniciais do ensino fundamental, três volumes para os anos finais do ensino fundamental e três volumes para o ensino médio. Tanto para os anos finais quanto para o ensino médio, os volumes referem-se a cada uma das três áreas: Linguagens e Códigos, Ciências da Natureza e Ciências Humanas, seguindo, em linhas gerais, a proposta dos Parâmetros Curriculares Nacionais para o ensino médio (BRASIL, 2000).

Os documentos foram formulados em conjunto por uma Coordenação Geral (subsecretários, gerentes e subgerentes da secretaria de educação); uma comissão curricular (professores, equipe de apoio e assessora); duas consultoras gerais; especialistas em Linguagens e Códigos, Ciências da Natureza e Ciências Humanas, Educação Ambiental, Educação Especial, Educação Étnico-Racial, Educação Indígena, Educação do Campo e Educação de Jovens e Adultos; professores-referência e colaboradores da rede estadual; e técnicos das Superintendências Regionais de Educação. Essa amplitude da equipe faz presumir um trabalho colaborativo, com sucessivas reuniões e deliberações e muitas instâncias críticas de análise e reformulação dos documentos. 
O extenso arrolamento dos créditos de autoria do documento, para além de assegurar documentalmente o trabalho de elaboração de que participaram diferentes agentes, faz parte de uma estratégia utilizada também em outros documentos públicos do campo da educação. Por exemplo, ao analisar o Catálogo do Programa Nacional do Livro Didático para o Ensino Médio (PNLEM) ressaltamos que:

[...] Para além das inelutáveis exigências editoriais, toda essa descrição ou apresentação dos órgãos e equipes responsáveis parecem querer encenar a ideia de um exaustivo trabalho coletivo, que resulta de muitos interesses ou perspectivas em diálogo, embora estejam todos subordinados à mesma hierarquia institucional (DALVI, 2011, p. 162).

Essa presunção a que somos induzidos coopera: a) no propósito de legitimação dos documentos; e b) no abalo do discurso que reiteradamente assinala as políticas curriculares brasileiras como oriundas de movimentos verticais ("de cima para baixo").

Na apresentação do CBEE-ES (ESPÍRITO SANTO, 2009a, p. 5), assinada pelo então secretário de estado da educação do Espírito Santo, Haroldo Corrêa da Rocha, podemos vislumbrar alguns contornos da concepção de educação que subsidia as políticas públicas da área e, por conseguinte, o CBEE-ES: “[...] a educação é fundamental na democratização do acesso de todos os cidadãos à qualidade de vida e alcance de objetivos, quer sejam individuais ou coletivos" (p. 5). Ou seja, a educação é vista como fundamental na democratização do acesso à qualidade de vida e à consecução de objetivos - donde parece ser possível depreender uma visão prática ou objetivista de educação, pouco alinhada à ideia de uma educação para si ou a uma ideia mais ampla de educação, que incorpore a dimensão subjetiva, pessoal e não utilitarista. Essa visão, supostamente, seria pouco propícia à discussão do trabalho com a literatura e a leitura literária de modo que incorpore o tensionamento entre "formação para literatura" e "formação pela literatura" (REZENDE, 2011) e, ainda mais, à proposta de uma "educação como transformação", como rasura à ideia de uma "educação como formação" (ROCHA, 2006).

Também podemos vislumbrar contornos da compreensão sobre o papel e os desafios da rede estadual de ensino: "Questões como a melhoria da qualidade das aprendizagens, a necessidade de maior envolvimento das famílias com a escola, a complexidade que envolve a infância e a juventude, além do avanço que precisamos consolidar na gestão [...] são alguns dos desafios postos hoje 
à eficiência da rede estadual de ensino" (ESPÍRITO SANTO, 2009a, p. 5). A ideia de "eficiência", originária do campo da gestão, e a menção à complexidade (como palavra de alta carga semântica no interior de discussões epistemológicas vinculadas à defesa de um "paradigma da complexidade") talvez sinalizem o fulcro ideológico - consciente ou não - de produção do documento em análise.

Outro ponto a ser sinalizado é que a correlação, numa única página ( $\mathrm{p}$. 5), entre: a) "melhoria da qualidade" - sem maiores detalhamentos sobre o que se chama de "qualidade"; b) apelo ao "avanço"; c) afirmação de que "[...] a Secretaria de Estado da Educação elaborou e está implementando o Plano Estratégico Nova Escola" (grifos nossos); e d) partilhamento na responsabilidade pela "[...] oferta de uma educação de qualidade incomparável à sociedade capixaba" - tudo isso conjuntamente - permite compreender certa persistência (ainda que difusa) de um ideário que Gadotti (1999) apresentou como sendo "[...] o mais vigoroso movimento de renovação da educação depois da criação da escola pública burguesa", ou seja, a proposta da "Pedagogia Nova" (SAVIANI, 2007), também identificada por "Escola Nova", de que "[...] a educação fosse instigadora da mudança social e, ao mesmo tempo, se transformasse porque a sociedade estava em mudança" (GADOTTI, 1999, p. 142).

Isso poderia ser reforçado quando constatamos que a apresentação do CBEE-ES, reproduzida nos oito volumes, afirma ainda que "[...] a fase mais complexa inicia-se agora", ou seja, posteriormente à elaboração do documento curricular, e que "[...] seu apoio e dedicação [do professor da rede estadual] são tão importantes quanto na fase anterior" (ESPÍRITO SANTO, 2009a, p. 5) ou seja, é no trabalho docente em classe, no desenvolvimento do ensino, que a efetividade das propostas será posta a prova, donde se explica sua valorização no desenvolvimento das técnicas e tecnologias do ensino.

Essa valorização do método pode ser constatada quando consideramos que a parte referente à disciplina de Língua Portuguesa no volume do CBEE-ES dedicado à área de Linguagens no ensino médio é composta de 15 páginas, assim distribuídas: a) 2 para a apresentação geral da disciplina; b) 2 para a apresentação das contribuições da disciplina (Língua Portuguesa) para a formação humana; c) 2 para a apresentação dos objetivos da disciplina (divididos em objetivos para "Língua", "Linguagem", "Literatura" e "Cultura e Conhecimento de Mundo"); d) 2 para alternativas ou sugestões metodológicas; e) 6 para organização das competências, habilidades e conteúdos/tópicos da disciplina; f) 1 para referências bibliográficas. Ou seja: descontada a organização curricular por ano do ensino médio e a listagem de referências, que ocupam juntas 7 páginas do documento, restam 8 páginas (itens a, b, c e d), das quais $2(25 \%)$ dizem respeito a alternativas ou sugestões metodológicas que, normalmente, se restringem à apresentação de técnicas de ensino. 
Não nos parece que certa permanência do ideário escolanovista, no documento, por si só constitua um problema, visto que se trata de "[...] um movimento complexo e contraditório" (GADOTTI, 1999, p. 148). No entanto, o fato de o plano estratégico para a educação elaborado pela gestão 2008-2011 (da qual a elaboração do CBEE-ES faz parte) decidir nomear-se "Nova Escola" - realizando uma menção explícita, direta e afirmativa do movimento - merece consideração atenta.

Algumas ponderações sobre a materialidade do documento e suas possíveis reverberações nas propostas para o trabalho com a literatura e a leitura literária

Ao lançarmos nosso olhar ao CBEE-ES, agora entendido como um objeto cultural, não podemos ignorar aspectos referentes à sua materialidade, pois concordamos com Chartier (2002) quando afirma que a forma material de um texto contribui para modelar expectativas do leitor, pois “[...] os textos não existem fora dos suportes materiais [...]. Contra a abstração dos textos, é preciso lembrar que as formas que permitem sua leitura, sua audição ou sua visão participam profundamente da construção de seus significados" (CHARTIER, 2002, p. 61-62). Conforme já aludimos noutra circunstância, dispositivos gráficos e de difusão utilizados assumem tanta relevância como o próprio conteúdo linguisticamente desenvolvido, pois são decisivos na produção de sentido - razão pela qual é pertinente (e necessário) levar em consideração o papel expressivo dos elementos verbais, visuais e de qualidade técnica que constituem esses mesmos objetos (DALVI, 2011, p. 158).

Assim, talvez seja importante considerar que o CBEE-ES tem duas versões "idênticas", todavia em suportes distintos (portanto, "não idênticas"): uma versão impressa e uma versão eletrônica, em .pdf, disponível no sítio eletrônico da Secretaria de Estado da Educação (SEDU). O texto, o layout, a diagramação, tudo é bastante similar, sendo a principal diferença, realmente, em relação ao suporte. Em ambos os casos, o documento passa a impressão de bom tratamento editorial e boa revisão, mas não há explicitação nos volumes de quem seriam os capistas, editoradores, editores, ilustradores, revisores, etc. (e nem há informações sobre o sistema de impressão, colagem, tiragem etc.): ou seja, esse trabalho "por trás", de dar forma material ao impresso, não é reconhecido como um trabalho "autoral" (ou seja, que precise ser "assinado") - e, portanto, não é reconhecido como algo que contribua relevantemente para a produção de sentidos do documento. Essa ausência no documento institucional reverbera no currículo proposto pelo CBEE-ES para a disciplina de Língua Portuguesa no ensino médio, pela baixa menção à abordagem material (layout, diagramação, impressão etc.) dos textos no processo de educação linguística e literária, con- 
tinuando a reiterar-se uma visão (idealista) de texto desentranhada das formas e condições de sua existência - o que, do ponto de vista curricular, é um dado bastante significativo.

Por exemplo, dentre os quatro objetivos enumerados para o trabalho com a literatura (p. 68), em nenhum deles se menciona o estudo comparado das diferentes versões de um texto literário; de igual modo, no bojo das "Principais alternativas metodológicas" (p. 69-70), não se menciona em qualquer ponto a questão da existência física dos textos, as diferenças recepcionais em função dos suportes, os protocolos de leitura vislumbrados a partir das diferentes versões ou formas materiais de um texto. Por isso mesmo, é importante atentar para o alerta que Zilberman (2007) faz sob a fórmula de "não ao texto, sim o livro". Ou seja: não basta, na escola, que coloquemos o texto em sala de aula, como existência abstrata, cuja produção de sentido seria desentranhada de suas diferentes formas e materialidades, ou seja, o texto desvinculado da história dos efeitos que produzem socioculturalmente suas variadas "objetificações", ignorando que sua leitura é produzida no tensionamento das leituras possíveis a partir de diferentes dispositivos, incluindo aqueles relacionados à edição, à publicação, à circulação.

De acordo com Chartier (2007):

[...] convém lembrar que a produção, não apenas de livros, mas dos próprios textos, é um processo que implica, além do gesto da escrita, diversos momentos, técnicas e intervenções, como as dos copistas, dos livreiros editores, dos mestres impressores, dos compositores e dos revisores. As transações entre as obras e o mundo social [...] concernem mais fundamentalmente às relações múltiplas, móveis e instáveis, estabelecidas entre o texto e suas materialidades, entre a obra e suas inscrições. O processo de publicação [...] é sempre um processo coletivo que requer numerosos atores e não separa a materialidade do texto da textualidade do livro (p. 12).

Assim, é necessário problematizar e ensinar a respeito das variadas formas pelas quais os textos ficcionais e não ficcionais são lidos, em suas diferentes materialidades e as distintas inscrições das obras: e um documento curricular que desconsidera isso desde seu projeto editorial muito pouco provavelmente irá incorporar tal proposta como dispositivo pedagógico inarredável de uma formação leitora integral e crítica. Dito de outro modo, parece-nos que quem não aprendeu a atentar às diferenças na produção de sentidos entre ler, por 
exemplo, um poema manuscrito em um caderno, publicado em um livro autoral de poemas artesanal, em grande tiragem ou em versão de bolso, inserido em uma antologia, rabiscado na porta de um banheiro, dado a ler em uma prova de concurso, pichado na parede de uma grande cidade, reproduzido como postagem no Facebook ou transformado em ilustração de conteúdo em um livro didático é um leitor para quem a escola não cumpriu plenamente seus propósitos. E, seja na materialidade do CBEE-ES, seja no conteúdo linguisticamente explicitado, essa preocupação não se evidencia.

Seguindo adiante nas ponderações sobre a materialidade do documento, é importante saber que a versão que chegou aos professores da rede e às escolas foi impressa. Essa versão impressa vem em papel de altíssima qualidade (alta gramatura, papel com brilho) e serve-se de modernas técnicas de impressão, como a impressão em offset digital e a impressão a laser, além de vir protegida por uma vistosa caixa. Considerando que, "[...] às vezes, o essencial do que diz um texto ou um discurso está naquilo no que ele não diz. Está na forma em que o diz... mudar a mensagem política na sua forma supõe uma mensagem política mais profunda do emissor do que uma mudança do conteúdo da mensagem política” (BOURDIEU, CHARTIER, 2011, p. 253), podemos supor que essa opção por evidenciar alto investimento gráfico-editorial na produção e distribuição do CBEE-ES vem reforçar a ideia de que a gestão 2008-2011 do governo do estado (exercida, então, por Paulo César Hartung Gomes) investiu "pesado" na educação pública (reforma de escolas, proposição de novo plano de cargos e salários do magistério, oferta de cursos de formação continuada, criação de programas de ampliação da jornada escolar e de oferta de cursos de idiomas etc.) - discurso propagado à exaustação pela SEDU e órgãos correlatos, muitas vezes com fins eleitorais, instituindo, supostamente, um marco quanti-qualitativo na controversa história da educação capixaba.

Essa hipótese, apresentada no parágrafo anterior, poderia ser reforçada pela retomada do discurso da apresentação do CBEE-ES, assinado pelo então secretário de estado da educação, que afirma:

[...] a Secretaria de Estado da Educação elaborou e está implantando o Plano Estratégico Nova Escola, que consiste numa agenda de projetos e ações prioritários para o período de 2008-2011. A construção do Novo Currículo da Educação Básica, como um plano único e consolidado, nesse contexto, sem dúvida, é um dos projetos considerados mais importantes e de impacto inigualável para o alcance da melhoria da qualidade [...] (ESPÍRITO SANTO, 2009a, p. 5, grifos nossos). 
Se o projeto é dos mais importantes e é de "impacto inigualável" - sem qualquer outro parâmetro que institua um universo de comparação -, podemos supor implícita a ideia de "impacto inigualável" a tudo o que já foi feito do gênero na história da educação do Espírito Santo: majorando a importância da iniciativa de gestão da qual o CBEE-ES seria tributária. Isso, certamente, tem impactos discursivos na legitimação da proposta curricular, funcionando como argumento de confiabilidade e mesmo de autoridade.

Uma leitura do volume dedicado à área de Linguagens e Códigos para o ensino médio e uma discussão em torno do trabalho com a literatura e a leitura literária

O sexto volume do CBEE-ES, dedicado à área de Linguagens e Códigos no ensino médio (ESPÍRITO SANTO, 2009b), com o qual lidamos diretamente, é dividido em três partes: uma "Apresentação" (p. 9-20), um "Capítulo Inicial" (p. 21-56) e um "Capítulo Ensino Médio" (p. 57-126). O "Capítulo Inicial”, por sua vez, é subdividido em cinco tópicos: "O processo de construção do documento curricular"; "Pressupostos teóricos"; "A diversidade na formação humana"; "Dinâmica do trabalho educativo"; e "Referências". Já o "Capítulo Ensino Médio", referindo-se especificamente à área, subdivide-se em "Língua Portuguesa", "Arte", "Educação Física" e "Língua Estrangeira Moderna - Inglês". Embora tenhamos todo o conjunto de oito volumes - e, em particular, os itens "Apresentação" e "Capítulo Inicial" do volume a que nos dedicamos - em mente, nossas reflexões incidirão, privilegiadamente, sobre as prescrições e recomendações curriculares atinentes à Língua Portuguesa (p. 63-80) e, em particular, ao trabalho com literatura e leitura literária, mas considerando que as concepções de língua e de linguagem atravessam toda proposta de educação literária que se possa fazer.

No item "6.1 Língua Portuguesa", afirma-se: a) que "[...] toma-se o conhecimento linguístico-cultural como resultado de um processo dinâmico - como algo aberto e inacabado, favorecido pela interação sujeito-objeto, mediado pelo professor", b) que ganha tônica "o saber linguístico pertinente" e c) que "o aluno deverá operar com o conhecimento produzido da perspectiva de sua incompletude, o que só é possível por meio de uma rede de relações construída em momentos partilhados com o outro", sendo d) a pesquisa "fundamento da formação intelectual" (ESPÍRITO SANTO, 2009b, p. 63). Vemos, nessas considerações iniciais, a convivência de fundamentos teóricos díspares, como as teorias interacionistas (de matriz piagetiana) e sócio-históricas (de matriz vigotskiana), e a incorporação de perspectivas contemporâneas, como a ideia de Morin (2001), de um saber linguístico pertinente, além da defesa da pesquisa como fundamento da formação intelectual. 
Adiante, mas ainda no mesmo item, o documento afirma entender a língua "como um objeto histórico, irregular, variável, gerenciado por usuários" (p. 63, grifos nossos) - e o que nos espanta é o uso da ideia de gerenciamento para se falar dos diferentes usos linguísticos, bem como a ideia de transformar o falante em usuário da língua, restringindo, em certa medida, o alcance subjetivo da identificação identitária como falante nativo.

O documento diz, ainda, assumir uma "concepção interacionista, funcional e discursiva da língua(gem)" (p. 63), fundamentada em autores de filiações díspares tais como João Wanderley Geraldi, Ingedore Koch e Irandé Antunes - citando, ainda, sociólogos divergentes entre si como Roberto DaMatta, Manuel Castells e David McNally, para falar das relações entre língua, sociedade e educação.

De maneira aparentemente contraditória, o CBEE-ES afirma que na escola o sujeito (aluno) terá “[...] a oportunidade de recorrer às práticas orais e escritas do sistema linguístico, com suas regras fonológicas, morfológicas, sintáticas e semânticas, para, por meio da língua, construir seu saber formal, não desconsiderando os saberes informais que ele traz consigo" (ESPÍRITO SANTO, 2009b, p. 66). Lemos nesse trecho uma retomada de certa tradição estrutural de compreensão das práticas orais e escritas, que reitera a língua como sistema articulado em diferentes níveis: fonológico, morfológico etc. - o que parece contrariar a fundamentação teórica assumida até então.

Essa aparente pouca clareza teórica poderia ser vista, por um lado, como tributária de uma situação da área de Educação como um todo - por exemplo, Siomara Borba Leite (2000) aponta uma reiterada afirmação de fragilidade teórico-metodológica dos trabalhos na área; e, por outro lado, poderia ser lida como relacionada a uma política que induz a produção de esvaziamentos ou diluições onto-epistemológicas, cujo desdobramento seria a construção de "mosaicos" teóricos nos quais diferentes correntes político-pedagógicas se reconheceriam, minando, de antemão, possíveis críticas, tensionamentos e embates. Outro ponto problemático é que o documento referencia obras que não são mencionadas no desenvolvimento do texto, deixando implícito, contudo, que viria delas algum subsídio para as propostas curriculares - mas sem permitir clareza nesse sentido, e, consequentemente, minimizando as possibilidades de questionamento ou refutação.

A literatura só será mencionada explicitamente a partir da quinta página das 15 (p. 63-77) que compõem todo o currículo proposto para a disciplina de Língua Portuguesa no ensino médio:

No caso da Literatura, essa propicia ao aluno o refinamento das habilidades de leitura e de escrita, capacita-o a lidar com o simbólico e a 
interagir consigo mesmo, com o outro e com o mundo em que vive, possibilitando-lhe assumir uma postura reflexiva, tomando consciência de si e do outro em relação ao universo letrado, tornando-se capaz de ser protagonista de uma ação transformadora. A Literatura propicia, ainda, uma reflexão política ao educando em reconhecimento do ser humano como um ser histórico social que sofre transformações com o decorrer do tempo (ESPÍRITO SANTO, 2009b, p. 66-67).

Vemos, neste trecho, a perpetuação de discursos que atribuem à Literatura funções, tais como refinar habilidades de leitura e escrita, capacitar à interação, tomar consciência de si e do outro, ser protagonista de ação transformadora, realizar reflexão política, que, embora pertinentes, não põem em primeiro plano a literatura como arte da palavra - embora, como arte, ela possa efetivamente contribuir para tudo o que foi mencionado. A dimensão lúdica, que se insurge contra uma apreensão pragmática, ou seja, a literatura entendida como jogo, como fruição fica parecendo secundária no contexto (e esse enfrentamento contra a captura do tempo e da inteligência humana pela domesticação da vontade talvez seja justamente a contribuição mais interessante da arte - e não apenas da literatura).

Na sequência, os objetivos da disciplina são apresentados a partir de eixos ("elementos que fundam e direcionam os princípios da formação do aluno" - ESPÍRITO SANTO, 2009b, p. 67), a saber, "Língua", "Linguagem" e "Literatura". Com relação à Literatura, são apresentados, em síntese, os seguintes objetivos: "Criar espaço para vivências e cultivos de emoções e sentimento humanos", "experienciar situações em que se reconheça o trabalho estético da obra literária", "Favorecer a produção de lócus em que se compreendam as transformações histórico-socioculturais pelas quais o homem passa, por meio da linguagem literária", "promover o letramento múltiplo" e "possibilitar o conhecimento das escolas literárias, obras e autores, inclusive da literatura capixaba" (p. 68).

Prevê-se, como alternativa metodológica, considerar o texto "o ponto de partida e de chegada", "ensinar o aluno-leitor a fixar objetivos e a ter estratégias de leitura, de modo a perceber que essa depende da articulação de várias partes que formam um todo" (p. 69), preparar a leitura a partir de ações de "descobrir conhecimentos prévios", "discutir o vocabulário do texto", "explorar a seleção do tema", "levantar palavras-chave" e "exercitar inferências sobre o texto" (p. 69). Vemos que, embora conste como um dos objetivos do trabalho com a literatura e a leitura literária, "a vivência e o cultivo de emoções e sentimentos humanos" (p. 68), nas recomendações metodológicas, não se manifesta. Questionamos, também, a defesa do trabalho com "parlendas, cantigas de roda e quadrinhas", 
porque nos parecem gêneros inadequados para o trabalho nos anos finais da educação básica (já que, tradicionalmente, explorados de modo exaustivo nos anos inicias do ensino fundamental).

Na listagem de conteúdos e tópicos, o currículo enumera conteúdos que retomam a historiografia literária de matriz positivista do séc. XIX, e apresenta como conteúdos uma listagem de temas relacionados à perspectiva das escolas literárias em correlação (como consequência direta) com contextos de época: por exemplo, são listados "Literatura Medieval Portuguesa", "O ciclo do Humanístico e Renascentista [...]", "Arte barroca portuguesa e brasileira. O barroco mineiro. Arcadismo português e brasileiro. Arcádia mineira e a inconfidência" (ESPÍRITO SANTO, 2009b, p. 72-76) etc. Assim, é possível depreender que, embora o discurso do CBEE-ES incorpore importantes avanços político-pedagógicos, contudo, ainda se ressente de uma forte herança colonialista e de um modelo de estudos literários que atravessou parte da história do séc. XX, mas que já foi exaustivamente debatido e problematizado na atualidade: um modo de vinculação direta entre contexto e produção literária e de ordenação linear/ cronológica de estéticas e sensibilidades.

Uma contribuição importante na listagem de conteúdos e tópicos, e que atenua os problemas sinalizados, é a presença de temas como: "A inquisição e seus efeitos maléficos sobre a cultura brasileira" (p. 72), "Processos da construção da nacionalidade no Brasil", "Ética e moral na literatura realista/naturalista", "A mulher em linguagem machadiana", "A desconstrução do índio e do negro pelo Realismo" (p. 73), "Literatura moderna no Brasil em seus três momentos e o projeto de uma identidade nacional", "O Cinema Novo e o Cinema de Glauber Rocha", "Racismo, preconceito e discriminação", "Literatura feminina e feminista", "Literatura homoerótica" (p. 75) etc.

\section{Considerações finais}

Em suma, no que diz respeito às orientações, normatizações e prescrições no tocante ao trabalho com a literatura e a leitura literária, depreende-se, nas análises, que haja a permanência de perspectivas tradicionais (como o foco na relação diretiva entre contexto social e produção literária e na historiografia positivista), todavia em correlação com mudanças requeridas por concepções renovadas ou renovadoras, tais como o foco na interação texto-leitor e na constituição da subjetividade leitora - embora isso ainda seja bastante tímido, como visto na proposição de alternativas metodológicas. Ressalta-se a ausência de 
um tratamento que leve em conta a dimensão material das obras literárias e que resista contra a captura pragmática do texto literário.

Evidentemente, há um largo espaço entre o textualmente previsto no CBEE-ES e o experienciado nas práticas cotidianas de ensino-aprendizagem em Língua Portuguesa, no ensino médio. Todavia, não foi nosso propósito estudar essa correlação ou enfrentamento. Detivemo-nos ao documento porque acreditamos que seja importante discutir o que o poder público emana, a partir do lugar discursivo que ocupa, como orientação curricular oficial para o trabalho com literatura e leitura literária na educação básica.

Se o documento deve ser interrogado de uma perspectiva que leve em conta o lugar ocupado por quem enuncia o que enuncia, parece possível supor que a voz que se ouve a partir do texto oficial é a voz, por um lado, desejosa de aceitação (disto a tentativa de alinhavar múltiplas perspectivas teórico-metodológicas e político-pedagógicas em um único documento) e reverberação, mas, de outro, uma voz ainda frágil no que diz respeito à consistência e, assim, à pertinência e relevância das propostas para o trabalho com a literatura e a leitura literária na escola básica de nível médio no estado do Espírito Santo.

\section{REFERÊNCIAS}

BENTO, Maria da Conceição Reis Lima. A língua portuguesa na educação básica: o discurso sobre a reorganização curricular e a sua recontextualização pedagógica. Tese (Doutorado em Educação) - Universidade do Minho, Minho, 2009.

BERENBLUM, Andra. A invenção da palavra oficial: identidade, língua nacional e escola em tempos de globalização. Belo Horizonte: Autêntica, 2003.

BOURDIEU, Pierre; CHARTIER, Roger. A leitura: uma prática cultural. In: CHARTIER, R. (Org.). Práticas de leitura. 5. ed. São Paulo: Estação Liberdade, 2011, p. 229-253.

BRASIL. Parâmetros Curriculares Nacionais do Ensino Médio. Brasília: MEC/SEB, 2000.

. Parâmetros Curriculares Nacionais (Séries Finais do Ensino Fundamental: terceiro e quarto ciclos). Brasília: MEC/SEB, 1998.

. Parâmetros Curriculares Nacionais (Séries Iniciais do Ensino Fundamental: primeiro e segundo ciclos). Brasília: MEC/SEB, 1997.

. Orientações curriculares para o ensino médio, v. 1 (Linguagens, Códigos e Suas Tecnologias). Brasília: MEC/SEB, 2004, p. 49-86. 
CHARTIER, Roger. Inscrever e apagar: cultura escrita e literatura. São Paulo: Unesp, 2007. . Os desafios da escrita. São Paulo: Unesp, 2002. . A história cultural entre práticas e representações. Lisboa: Difel, 1988.

DALVI, Maria Amélia. Drummond: a invenção de um poeta nacional pelo livro didático. Vitória: Edufes, 2011.

ESPÍRITO SANTO (Estado). Currículo Básico da Escola Estadual. 8v. Vitória: SEDU, 2009a. Disponível em: < http://www.educacao.es.gov.br/download/sedu_curriculo_basico_escola_estadual.pdf $>$. Acesso em: 11/11/2013.

. Ensino Médio: área de Linguagens e Códigos. Vitória: SEDU, 2009b. Disponível em: $<$ http://www.educacao.es.gov.br/download/sedu_curriculo_basico_escola_estadual. pdf $>$. Acesso em: 11/11/2013.

GADOTTI, Moacir. História das ideias pedagógicas. 3. ed. São Paulo: Ática, 1999.

LEITE, Siomara Borba. Teoria: desafio e perspectiva na pesquisa em Educação. Perspectiva, Florianópolis, v. 18, n. 33, p. 125-134, jan./jul. 2000.

MARINHO, Marildes. Currículos da escola brasileira: elementos para uma análise discursiva. Revista Portuguesa de Educação, Minho, v. 20, n. 1, p. 163-189, 2007.

MORIN, Edgar. Os sete saberes necessários à educação do futuro. São Paulo: Cortez; Brasília: Unesco, 2001.

NÚMEROS do Brasil. Disponível em: < http:/www.todospelaeducacao.org.br/educacao-no-brasil/numeros-do-brasil/>. Acesso em 18/01/2014.

PINTO, Mariana Oliveira. Para a caracterização da disciplina de Língua Portuguesa no Ensino Básico. Millenium, Minho, v. 27, n. 1, abr. 2003.

REZENDE, Neide Luzia de. O ideal de formação pela literatura em conflito com as práticas de leitura contemporâneas. In: SANTINI, Juliana (Org.). Literatura, crítica, leitura. Uberlândia, MG: EDUFU, 2011, p. 275-293.

ROCHA, Silvia Pimenta Velloso. Tornar-se quem se é: educação como formação, educação como transformação. In: FEITOSA, Charles; BARRENECHEA, Miguel Angel de; PINHEIRO, Paulo (Org.). Nietzsche e os gregos: arte, memória, educação. Rio de Janeiro: DP\&A; Faperj; Unirio; Brasília: Capes, 2006.

SAVIANI, Dermeval. História das ideias pedagógicas no Brasil. Campinas: Autores Associados, 2007.

SILVA, Tomaz Tadeu da. Documentos de identidade: uma introdução às teorias do currículo. 2. ed. Belo Horizonte: Autêntica, 2005.

SILVA, Vanessa Souza da. O documento reorientação curricular de língua portuguesa da SEE do estado do Rio de Janeiro (2006): um trabalho com os gêneros. Veredas - Revista de Estudos Linguísticos, Juiz de Fora, v. 2, n. 9, p. 128-143, jan. 2009. 
SOARES, Lúcia. Qual o papel da língua portuguesa na política educativa em Timor Leste? In: CONGRESSO PORTUGAL E OS PAÍSES AFRICANOS DE LÍNGUA OFICIAL PORTUGUESA. Cooperação na Área da Educação. Anais... Lisboa, CEA, 2011, p. 95-102.

ZILBERMAN, Regina. Letramento literário: não ao texto, sim ao livro. In: PAIVA, Aparecida et al. (Org.). Literatura e letramento: espaços, suportes e interfaces. Belo Horizonte: Autêntica; CEALE/FAE/UFMG, 2007.

Texto recebido em 30 de janeiro de 2014. Texto aprovado em 27 de fevereiro de 2014. 
